\title{
PENGARUH PEMBERIAN PELATIHAN MENULIS KREATIF TERHADAP KETERAMPILAN MEMBUAT DONGENG ANAK
}

\author{
Rosa Imani Khan ${ }^{1}$, Widi Wulansari ${ }^{2}$ \\ Fakultas Keguruan dan Ilmu Pendidikan, Universitas Nusantara PGRI Kediri ${ }^{1,2}$ \\ Email: rossa_rose@unpkediri.ac.id ${ }^{1}$, widiwulansari@unpkediri.ac.id ${ }^{2}$ \\ Khan, Rosa Imani. Widi Wulansari. (2021). Pengaruh Pemberian Pelatihan Menulis Kreatif terhadap \\ Keterampilan Menulis Dongeng Anak. Jurnal Pelita PAUD, 6(1), 15-23. \\ doi: https://doi.org/10.33222/pelitapaud.v6i1.1329
}

Diterima: 25-06-2021

Disetujui: 27-10-2021

Dipublikasikan: 21-12-2021

\begin{abstract}
Abstrak: Tujuan penelitian ini adalah untuk mengetahui adakah pengaruh pemberian pelatihan menulis kreatif terhadap keterampilan menulis dongeng anak. Subjek dalam penelitian ini adalah 50 orang sebagai kelompok eksperimen dan 50 orang lagi sebagai kelompok kontrol. Pemilihan sampel dilakukan dengan teknik convenience sampling. Jenis penelitian ini adalah penelitian kuantitatif tipe quasi experimental yang menggunakan desain non-randomized pretest-postest control group. Pengumpulan datanya menggunakan kuesioner berbentuk skala likert. Analisis datanya dilakukan dengan teknik uji t-dua sampel. Nilai sig yang telah diperoleh sebesar 0,0001 , kurang dari nilai alpha yang ditetapkan yaitu 0,05. Ini berarti pelatihan menulis kreatif telah terbukti secara empiris memberikan pengaruh yang signifikan terhadap keterampilan menulis dongeng anak. Pengaruh yang diberikan bersifat positif. Ini tampak dari 231 peserta, terdapat kenaikan hasil posttest pada 188 peserta Hal ini berarti pemberian pelatihan menulis kreatif mampu meningkatkan keterampilan menulis dongeng anak pada subjek penelitian. Pelatihan menulis kreatif dalam penelitian ini dapat merangsang munculnya potensi menulis dongeng dalam diri para pendidik PAUD. Keterampilan menulis dongeng yang baik akan sangat bermanfaat untuk meningkatkan kualitas kemampuan profesional mereka termasuk meningkatkan keberhasilan pembelajaran yang dilakukan karena banyak sekali aspek perkembangan anak usia dini yang dapat diasah melalui kegiatan mendongeng.

Kata kunci: menulis kreatif, dongeng
\end{abstract}

Abstract: The purpose of this study was to determine whether there was an effect of providing creative writing training on children's fairy tale writing skills. The subjects in this study were 50 people as the experimental group and 50 people as the control group. Sample selection was done by convenience sampling technique. This type of research is a quasi-experimental type of quantitative research that uses a non-randomized pretest-posttest control group design. The data collection uses a questionnaire in the form of a likert scale. The data analysis was carried out using a two-sample ttest technique. The sig value that has been obtained is 0.0001, less than the specified alpha value of 0.05. This means that creative writing training has been empirically proven to have a significant effect on children's fairy tale writing skills. The influence given is positive. This can be seen from 231 participants, there is an increase in posttest results in 188 participants. This means that the provision of creative writing training can improve children's storytelling writing skills on the research subject. Creative writing training in this study can stimulate the emergence of the potential for writing fairy tales in PAUD educators. Good fairy tale writing skills will be very useful to improve the quality of their professional abilities, including increasing the success of learning carried out because there are many aspects of early childhood development that can be honed through storytelling activities.

Keywords: creative writing, fairy tales

(C) 2021 Rosa Imani Khan, Widi Wulansari Under the license CC BY-SA 4.0

http://jurnal.upmk.ac.id/index.php/pelitapaud 


\section{PENDAHULUAN}

Dalam hidup, manusia tak akan lepas dari aktivitas literasi. Literasi penting dilakukan guna memperoleh informasi yang dibutuhkan oleh manusia. Literasi utamanya berhubungan dengan bahasa dan bagaimana bahasa itu digunakan. Kemampuan literasi adalah kemampuan memahami, melibatkan, menggunakan, menganalisis dan mentransformasi teks (Sutarma \& Adnyana, 2014). Definisi lama literasi adalah kemampuan membaca dan menulis, tetapi saat ini istilah literasi mengalami perkembangan pengertian. Kini istilah literasi disandingkan dengan kata-kata lain, seperti literasi matematika, literasi sains, literasi membaca, dan lain-lain (Basyiroh, 2017).

Pengertian literasi berkembang meliputi proses membaca, menulis, berbicara, mendengar, membayangkan dan melihat. Saat individu sedang membaca, terjadi proses yang rumit yaitu proses kognitif, linguistik dan aktivitas sosial. Individu harus secara aktif melibatkan pengalaman sebelumnya, proses berpikir, sikap, emosi dan minat untuk memahami bacaan (Kuder \& Hasit, 2002).

Keterampilan menulis merupakan salah satu aspek keterampilan yang sangat penting dalam kehidupan manusia. Bila dikaitkan dengan kesehatan mental, semakin sering seseorang menulis, maka akan semakin sehat mentalnya. Ini terjadi karena melalui aktivitas menulis, beban psikologis yang dimiliki akan terekspresikan/terluapkan melalui tulisannya (Lowe, 2006). Kegiatan menulis terdapat dalam pelajaran Bahasa Indonesia dan memiliki berbagai macam jenis. Berdasarkan bentuknya, kegiatan menulis dibagi menjadi empat jenis, yaitu menulis narasi, deskripsi, argumentasi, dan eksposisi (Tarigan, 1994). Keseluruhan kegiatan menulis, terwujud dalam kegiatan menulis puisi, cerpen, pantun, berita, dongeng, dan lain-lain.

Aarne dan Thompson (Danandjaja, 1994) menjelaskan bahwa dongeng adalah cerita prosa rakyat yang tidak dianggap benar-benar terjadi. Dongeng diceritakan terutama untuk hiburan, meskipun kenyataannya banyak dongeng yang melukiskan kebenaran, mengandung pelajaran moral, atau sindiran. Dongeng biasanya mempunyai kalimat pembukaan dan penutup yang bersifat klise, misalnya dalam dongeng Jawa diawali dengan "Anuju sawijining dino..." dan diakhiri dengan kalimat penutup "A lan B urip rukun bebarengan kaya mimi lan mintuno". Pada dongeng Melayu biasanya diawali dengan kalimat "Sahibul hikayat", "Kata yang empunya ceritera.....", dan sebagainya. Dongeng tidak hanya berkisah tentang manusia, namun bisa kisah tentang binatang, tanaman, dan sebagainya. Pada dasarnya semua yang ada di sekitar kita dapat diangkat menjadi dongeng. Menarik tidaknya dongeng tergantung dari kreativitas pendongeng. Beberapa ahli menggolongkan jenis dongeng menjadi beberapa kelompok. Salah satunya penggolongan jenis dongeng oleh Anti Aarne dan Stith Thompson (Danandjaja, 1994) yang membagi jenis dongeng ke dalam empat golongan besar, yaitu: 1) dongeng binatang (animal tales), 2) dongeng biasa (ordinary folktales), 3) lelucon dan anekdot (jokes and anecdotes), dan 4) dongeng berumus (formula tales).

Mendongeng merupakan kegiatan yang tampaknya sepele, tetapi sangat berarti bagi perkembangan jiwa anak. Menurut Priyono (Priyono, 2001), mendongeng bila dilakukan dengan pendekatan yang sangat akrab akan mendorong terbukanya cakrawala pemikiran anak, sejalan dengan pertumbuhan jiwa sehingga mereka akan mendapat sesuatu yang sangat berharga bagi dirinya dan dapat memilih mana yang baik dan mana yang buruk. Cerita dari dongeng dapat dipetik manfaatnya, terutama dongeng-dongeng yang mengandung pesan moral. Oleh karena itu pendongeng harus pandai memilih dongeng yang sesuai dengan usia anak serta mengandung nilai pendidikan yang bermanfaat untuk anak. Di samping mengandung nilai-nilai yang bermanfaat bagi anak, kegiatan mendongeng merupakan metode terbaik untuk membuat anak belajar. Anak-anak sering menggunakan waktu belajar seenaknya. Dengan metode mendongeng, anak akan mendengarkan dengan penuh perhatian karena dongeng sangat menarik bagi anak-anak. Manfaat yang lain lagi dari bacaan dongeng untuk anak bila ditinjau dari jenis cerita yang berbasis kearifan lokal adalah 
P ISSN 2548-6284 E ISSN 2615-0360

Vol. 6 No. 1 Desember 2021

dapat menambah wawasan multikultural bagi si pembaca (Elia et al., 2010), sedangkan bacaan cerita/dongeng yang berbasis pendekatan saintifik akan dapat mengembangkan dimensi sikap ilmiah anak, yakni berpikir kritis, bersikap terbuka (open minded), skeptis dan objektif (Singh et al., 2016).

Mendongeng merupakan salah satu bentuk tradisi lisan sebagai sarana komunikasi dan merekam peristiwa-peristiwa kehidupan, sudah ada berabad-abad yang lalu. Tradisi lisan ini terus berkembang, dan pernah menjadi primadona bagi ibu atau nenek dalam mengantar tidur anak atau cucu mereka. Namun seiring dengan perkembangan teknologi yang semakin pesat dan faktor kesibukan yang semakin meningkat, tradisi mendongeng banyak ditinggalkan orang. Televisi, film, dan smartphone lebih menarik perhatian dibanding mendongeng. Seorang ibu yang biasanya mendongeng saat anaknya menjelang tidur seringkali tidak mengetahui bahwa anaknya sudah berangkat tidur karena asyik dengan acara televisi atau smartphonenya.

Saat ini, smartphone telah berevolusi menjadi sebuah barang dengan bentuk yang praktis dan menarik, diperkaya juga dengan fitur layar sentuh yang membuatnya sangat mudah dioperasikan oleh siapapun. Lebih lanjut lagi, Syahra (Syahra, 2006) menjelaskan bahwa seiring berkembangnya zaman, teknologi informasi dan komunikasi juga berkembang kian pesat, termasuk smartphone. Penggunaannya telah menjangkau ke berbagai kalangan masyarakat dari bermacam usia, bidang dan level pendidikan. Penggunaan oleh orang dewasa, biasanya untuk alat berkomunikasi, mencari informasi (browsing), membuka youtube, bermain game, dan lainnya. Sedangkan penggunaan pada anakanak, biasanya cuma sebatas untuk media belajar, bermain game, dan menonton video animasi.

Smartphone memang dapat diisi dengan bermacam-macam aplikasi yang menarik bagi anak, seperti berbagai permainan dan video animasi. Inilah alasan mengapa anak begitu mudah menyukai smartphone. Smartphone bersifat interaktif, mudah dioperasikan guna mencari informasi, menyajikan dimensi- dimensi gerak, suara, warna dan lagu sekaligus, serta tentu saja tidak dapat membalas dengan amarah disaat anak sedang merasa jengkel (Antara, 2017). Itu semua tidak diperoleh anak dari jenis media lain, seperti buku dan majalah. Aneka hal menarik yang disajikan smartphone tak pelak membuat anak betah berlama-lama menggunakan smartphone, sehingga penggunaan smartphone ini dapat menjadi berlebihan.

Survei yang dilakukan oleh situs parenting terbesar di Asia Tenggara, yaitu The Asian Parent, di tahun 2014 mengenai penggunaan perangkat seluler di kalangan anak-anak di Asia Tenggara menemukan bahwa 98\% anakanak di Asia Tenggara telah memakai perangkat seluler (smartphone). Anak-anak tersebut dapat memakai smartphone karena orangtuanya memberikan izin. Survei juga dilanjutkan dengan mengumpulkan informasi tentang mengapa orangtua mengizinkan anaknya menggunakan smartphone, alasannya adalah sebagai berikut: 1) untuk keperluan pendidikan, 2) untuk hiburan, 3) untuk pengenalan teknologi sejak dini, 4) untuk membuat anak tenang, dan 5) karena gengsi. Rupanya data ini sejalan pula dengan hasil riset yang dirilis oleh Kementerian Informasi bekerjasama dengan UNICEF pada tahun 2014 bahwa 98\% anak dan remaja di Indonesia telah mengetahui tentang internet dan $79,5 \%$ diantaranya adalah pengguna internet (Islami, 2017).

Hasil penelitian Novitasari (Witarsa et al., 2018) menjelaskan bahwa bagi anak, memakai smartphone lebih menyenangkan bila dibandingkan dengan aktivitas bermain bersama teman sebayanya. Ini tidak lepas dari bermacam-macam aplikasi menarik yang ada dalam smartphone. Selain itu, orangtua yang mengizinkan anaknya untuk bermain smartphone agar anak menjadi lebih tenang dan tidak rewel, membuat anak semakin asyik dengan smartphone dan acuh terhadap dunia sekitarnya. Jika kondisi ini terus-menerus dibiarkan, maka tanpa disadari, anak dapat menjadi tergantung dengan smartphone. Ketergantungan inilah yang menjadi salah satu dampak negatif bagi perkembangan anak. Lebih jauh lagi, Chusna (Chusna, 2017) dalam penelitiannya menyatakan bahwa saat anak telah mengalami ketergantungan terhadap 
smartphone, waktu yang dimiliki oleh anak akan dapat terbuang sia-sia karena biasanya anak akan seringkali lupa waktu ketika sedang asyik menggunakan smartphone. Anak bisa kehilangan momentum terbaiknya untuk mengasah berbagai aspek perkembangannya, seperti kemampuan motorik, sosial, emosional, bahasa, dan lainnya.

Smartphone juga dapat dimanfaatkan sebagai salah satu jenis alat permainan modern yakni permainan yang dilakukan dengan menggunakan alat-alat teknologi yang telah berkembang/canggih di masyarakat dan dapat dimainkan sendiri tanpa teman bermain, sehingga jika anak seringkali lebih asyik dengan dirinya sendiri dan smartphone maka nilai karakter anak semakin hilang (Novrialdy, 2019; Saputra \& Ekawati, 2017; Syafryadin \& Boulahnane, 2021).

Untuk menanggulangi maraknya penggunaan teknologi smartphone yang berlebihan oleh anak serta berkembang pesatnya film-film atau cerita video impor yang kadang tidak sesuai dengan norma atau etika ketimuran, maka perlu dikembangkan kemampuan menulis dongeng anak agar lebih menarik dan terasa manfaatnya bagi anak. Dongeng memang merupakan cerita rekaan, tetapi tidak berarti dongeng tidak bermanfaat. Justru dongeng bisa mengaktifkan aspek intelektual, kepekaan, kehalusan budi, emosi, seni, fantasi, dan imajinasi. Tidak hanya mengutamakan otak kiri, tetapi juga otak kanan. Seiring dengan perkembangan zaman, kegiatan menulis dongeng sedikit demi sedikit terkikis oleh hiruk-pikuk kemajuan teknologi, terutama keberadaan smartphone (Utomo, 2013). Oleh karena itu, memandang banyaknya manfaat penting dari dongeng untuk perkembangan kualitas anak, maka diperlukan upaya untuk mengembangkan keterampilan menulis dongeng, agar budaya mendongeng dapat tumbuh subur lagi di kalangan masyarakat.

\section{Keterampilan Menulis}

Menurut Rosidi (Rosidi, 2009), keterampilan dalam linguistik berarti kesanggupan seorang pemakai bahasa untuk mempergunakan bahasanya dengan baik. Keterampilan linguistik tersebut adalah keterampilan menyimak, berbicara, membaca dan menulis.
Pengertian keterampila berbeda dengan kemampuan. Kemampuan (competence) adalah sesuatu yang masih ada di dalam batin, sedangkan keterampilan merupakan perwujudan apa yang ada di dalam batin seseorang. Seseorang akan terampil dalam bidang apapun, apabila ia dapat membiasakan diri dan banyak berlatih. Selain dengan membiasakan diri dan banyak berlatih, seseorang juga harus mempunyai niat dan motivasi yang kuat untuk memiliki keterampilan dalam bidang apapun. Niat yang kuat akan membantu dalam mengalami kesulitan yang dihadapi pada saat proses memiliki suatu keterampilan (Wiyanto, 2004). Berdasarkan pendapat di atas, dapat ditarik kesimpulan bahwa keterampilan yaitu kompetensi yang dimiliki seseorang dalam bidang apapun, karena adanya motivasi serta hasil dari proses membiasakan diri dan berlatih secara terus-menerus.

Menulis adalah menurunkan atau melukiskan lambang-lambang grafik yang menggambarkan suatu bahasa yang dipahami seseorang, sehingga orang lain dapat memahami bahasa dan lambang grafik tersebut. Artinya, bahwa menulis adalah suatu kegiatan yang tidak sekedar menggambarkan simbol-simbol grafis secara konkret, tetapi juga menuangkan buah pikiran, ide atau gagasan ke dalam bahasa tulis yang berupa ringkasan kalimat yang utuh dan dapat dikomunikasikan kepada orang lain. Berdasarkan pendapat di atas, dapat disimpulkan bahwa keterampilan menulis adalah kompetensi dalam mengungkapkan ide, gagasan, perasaan, dan pikiran ke dalam bahasa tulis secara jelas dan utuh untuk dapat dipahami dan dikomunikasikan kepada orang lain (Tarigan, 1994).

\section{Menulis Kreatif}

Menulis kreatif menekankan pada sikap aktif seseorang untuk menulis, kemudian mampu menemukan proses kreatifnya agar tulisan menjadi baik dan menarik. Berbeda dengan "penulisan kreatif" kesannya terlalu statis. Penulisan kreatif lebih dekat ke karya yang sudah jadi, orientasinya pada hasil karya. Menulis kreatif adalah proses menuangkan ide atau gagasan sebagai wujud pengendalian pikiran-pikiran kreatif agar dapat menjadi 
Vol. 6 No. 1 Desember 2021

tulisan yang baik dan menarik. Menulis kreatif adalah ekspresi cara berpikir dalam menuangkan ide gagasan yang tidak biasa ke dalam bentuk tulisan yang beda. Maka menulis kreatif ini adalah menulis untuk sastra. Entah itu berupa puisi, cerpen, novel maupun dongeng (Yunus, 2015).

\section{Dongeng}

Menurut Nurgiyantoro (Nurgiyantoro, 2005), dongeng merupakan salah satu cerita rakyat (folktale). Dongeng berasal dari berbagai kelompok etnis, masyarakat, atau daerah tertentu di berbagai belahan dunia, baik yang berasal dari tradisi lisan maupun yang sejak semula diciptakan secara tertulis. Contoh dongeng yaitu: Kancil Mencuri Timun, Asalusul Gunung Tangkuban Perahu, Timun Mas, dan sebagainya. Dongeng adalah cerita rakyat yang tidak dianggap benar-benar terjadi oleh yang punya cerita dan dongeng tidak terikat oleh waktu maupun tempat. Dongeng diceritakan terutama untuk hiburan, walaupun banyak juga dongeng yang melukiskan kebenaran, berisi ajaran moral (Danandjaja, 1994). Kemunculan dongeng yang sebagai bagian dari cerita rakyat, selain berfungsi untuk memberi hiburan, juga sebagai sarana untuk mewariskan nilai-nilai yang diyakini kebenarannya oleh masyarakat pada waktu itu. Dongeng dan berbagai cerita rakyat yang lain dipandang sebagai sarana ampuh untuk mewariskan nilai-nilai, dan untuk masyarakat lama itu dapat dipandang sebagai satu-satunya cara (Nurgiyantoro, 2005). Dongeng adalah cerita prosa rakyat yang tidak dianggap benarbenar terjadi. Cerita ini ditujukan hanya untuk hiburan semata (Kurniawan, 2009). Ceritacerita dalam dongeng semata-mata hanyalah khayalan. Walaupun hanya cerita khayalan atau cerita bohongan, tetapi cerita dalam dongeng mengandung nilai-nilai luhur. Berdasarkan beberapa pendapat di atas, maka dapat ditarik kesimpulan bahwa dongeng adalah cerita rakyat yang isi ceritanya tidak benar-benar terjadi dan hanya ada dalam dunia khayal dan fungsinya sebagai hiburan masyarakat dan terdapat ajaran moral di dalamnya.

Berdasarkan penjelasan di atas, dipandang perlu untuk melaksanakan sebuah penelitian untuk mengetahui adakah pengaruh pemberian pelatihan menulis kreatif terhadap keterampilan menulis dongeng anak. Diharapkan informasi yang diperoleh dari penelitian ini dapat menjadi referensi praktis penelitian berikutnya untuk mengembangkan strategi sejenis pada materi yang lebih luas dengan bentuk-bentuk kegiatan lainnya guna melestarikan semangat untuk terus berupaya mengoptimalkan kualitas generasi penerus bangsa, khususnya anak-anak di usia dini, agar pemegang tongkat estafet kepemimpinan bangsa ini kelak memiliki sumber daya manusia yang berkualitas tinggi. Hipotesis penelitian ini adalah "Ada pengaruh pemberian pelatihan menulis kreatif terhadap keterampilan menulis dongeng anak".

\section{METODE PENELITIAN \\ Jenis Penelitian}

Jenis penelitian ini adalah penelitian kuantitatif tipe eksperimen semu atau quasi experimental. Quasi experimental adalah desain eksperimen yang dilakukan tanpa randomisasi, namun masih menggunakan kelompok konrol. Dibandingkan dengan desain pre eksperimental, eksperimen semu ini lebih baik karena melakukan kontrol terhadap beberapa variabel non-eksperimental dan ada kelompok kontrol sebagai kelompok komparatif untuk memahami efek perlakuan (Latipun, 2002).

\section{Waktu dan Tempat Penelitian}

Penelitian ini dilaksanakan pada tahun 2020, berlokasi di Kota Kediri, Jawa Timur.

\section{Subjek Penelitian}

Subjek dalam penelitian ini, sebagai kelompok eksperimen adalah 50 orang pendidik PAUD di wilayah Kediri Raya. Sedangkan sebagai kelompok kontrol adalah 50 orang pendidik PAUD juga di wilayah Kediri Raya. Kedua kelompok dipandang memiliki karakteristik yang sama secara umum untuk penelitian ini. Pemilihan sampel dilakukan dengan teknik convenience sampling, peneliti tidak mempunyai pertimbangan lain kecuali berdasarkan kemudahan saja.

\section{Prosedur}

Penelitian ini menggunakan desain nonrandomized pretest-postest control group (desain eksperimen ulang non-random). Menurut Latipun (Latipun, 2006), desain penelitian ini dilakukan dengan memberikan 


\begin{tabular}{|c|c|c|c|}
\hline $\begin{array}{c}\text { Aitem } \\
\text { Favorable }\end{array}$ & Skor & $\begin{array}{c}\text { Aitem } \\
\text { Unfavorable }\end{array}$ & Skor \\
\hline $\begin{array}{l}\text { Sangat Setuju } \\
\text { (SS) }\end{array}$ & 5 & $\begin{array}{l}\text { Sangat Setuju } \\
\text { (SS) }\end{array}$ & 1 \\
\hline Setuju (S) & 4 & Setuju (S) & 2 \\
\hline $\begin{array}{l}\text { Ragu-ragu } \\
\text { (RR) }\end{array}$ & 3 & Ragu-ragu (RR) & 3 \\
\hline $\begin{array}{l}\text { Tidak Setuju } \\
\text { (TS) }\end{array}$ & 2 & $\begin{array}{l}\text { Tidak Setuju } \\
\text { (TS) }\end{array}$ & 4 \\
\hline $\begin{array}{l}\text { Sangat Tidak } \\
\text { Setuju (STS) }\end{array}$ & 1 & $\begin{array}{l}\text { Sangat Tidak } \\
\text { Setuju (STS) }\end{array}$ & 5 \\
\hline \multicolumn{4}{|c|}{$\begin{array}{l}\text { pretest sebelum perlakuan diberikan dan } \\
\text { posttest setelah perlakuan, sekaligus ada } \\
\text { kelompok kontrol dan kelompok eksperimen. } \\
\text { Dalam desain ini, sampel ditetapkan dengan } \\
\text { tidak random. Desain eksperimen ini sedikit } \\
\text { lebih baik jika dibandingkan dengan desain } \\
\text { praeksperimen, karena dalam desain ini ada } \\
\text { kelompok kontrol. }\end{array}$} \\
\hline
\end{tabular}

Selain itu, teknik konstansi atau teknik untuk menyamakan subyek pada variabel menggunakan Matched Group Design, yaitu membagi kelompok menjadi kelompok kontrol dan kelompok eksperimen, kemudian melakukan matching antara kelompok kontrol dan eksperimen sebelum melakukan eksperimen. Proses penyamaan ini dilakukan dengan memilih subyek yang memiliki kemampuan berhitung sangat rendah, rendah, tinggi dan sangat tinggi, kemudian subyeksubyek tersebut dibagi rata dalam kelompok kontrol dan eksperimen. Desain penelitian adalah sebagai berikut (Latipun, 2002):

$$
\begin{aligned}
& \text { nonR } \mathrm{O}_{1} \rightarrow(\mathrm{X}) \rightarrow \mathrm{O}_{2} \\
& \text { nonR } \mathrm{O}_{1} \rightarrow(\mathrm{X}) \rightarrow \mathrm{O}_{2}
\end{aligned}
$$

Keterangan :

nonR : nonrandomisasi

$\mathrm{O}$ : pengukuran variabel tergantung

Perlakuan yang diberikan dalam penelitian ini adalah dengan memberikan pelatihan menulis kreatif untuk mengembangkan keterampilan menulis dongeng anak pada kelompok eksperimen. Penelitian berlangsung dengan memberikan manipulasi pada kelompok eksperimen selama empat hari, kemudian dilanjutkan dengan pengukuran keterampilan menulis dongeng anak pada hari berikutnya.

Data, Intrumen, dan Teknik Pengumpulan Data

Pengumpulan data dalam penelitian ini menggunakan kuesioner yang berisi pertanyaan-pertanyaan dalam bentuk skala likert. Skala ini memiliki aitem favorable dan unfavorable. Respon yang digunakan berjumlah empat, antara lain: SS (sangat setuju), S (setuju), RR (Ragu-ragu), TS (tidak setuju), dan STS (sangat tidak setuju). Alternatif respon pada masing-masing aitem memiliki skor yang berbeda, seperti yang termuat pada Tabel 1 berikut ini:

Tabel 1. Skor Respon Skala Keterampilan Menulis Dongeng Anak

\section{Teknik Analisis Data}

Analisis data dalam penelitian ini dilakukan dengan teknik uji t-dua sampel dengan bantuan SPSS for windows versi 16.

\section{HASIL PENELITIAN DAN PEMBAHASAN}

Uji prasyarat analisis yang dilakukan meliputi uji normalitas dan homogenitas untuk nilai pretest dan posttest dengan tujuan apakah data sampel layak untuk diuji hipotesisnya dengan statistika parametrik, yaitu Paired t-test. Berikut hasil dari uji asumsi dari nilai pretest dan posttest dengan sampel sebanyak 20 orang:

Tabel 2. Hasil Uji Normalitas dan Homogenitas Pretest dan Posttest

\begin{tabular}{rrrrrl}
\hline \multirow{2}{*}{ Nilai } & \multicolumn{2}{c}{ Normalitas } & \multicolumn{2}{c}{ Homogenitas } & Hipotesis \\
& Nilai & Sig. & Nilai & Sig. & \\
\hline Pretest & 1,444 & 0,031 & 1,669 & 0,021 & $\mathrm{H}_{0}$ \\
Posttest & 1,421 & 0,035 & 2,186 & 0,001 & diterima \\
& & & & & $($ Sig $>0,05)$ \\
\hline
\end{tabular}

Berdasarkan Tabel 2 di atas dapat disimpulkan bahwa sampel yang diambil tidak memenuhi pengujian asumsi sehingga dilakukan uji hipotesis dengan menggunakan statistika non parametrik.

Uji hipotesis dilakukan untuk melihat apakah ada perbedaan nilai pretest dan posttest pada keterampilan menulis dongeng. Berikut hasil uji hipotesis disajikan dalam tabel berikut ini: Tabel 3. Hasil Uji Hipotesis dengan Wilcoxon Signed Ranks

\begin{tabular}{lr}
\hline & Posttest - Pretest \\
\hline $\mathrm{Z}$ & -11.168 \\
Asymp. Sig. (2-tailed) & .000 \\
\hline
\end{tabular}


P ISSN 2548-6284 E ISSN 2615-0360

Vol. 6 No. 1 Desember 2021

Pada Tabel 3 di atas, dapat dilihat nilai sig sebesar 0,0001 sehingga dapat diartikan bahwa nilai sig kurang dari nilai alpha yang ditetapkan yaitu 0,05 . Kesimpulannya bahwa Ho ditolak dan $\mathrm{Ha}$ diterima. Ini berarti pelatihan menulis kreatif telah terbukti secara empiris memberikan pengaruh yang signifikan terhadap keterampilan menulis dongeng anak. Tabel 4. Perbedaan Hasil Pre Test \& Post Test

\begin{tabular}{|c|c|c|c|c|}
\hline & & $\mathrm{N}$ & $\begin{array}{l}\text { Mean } \\
\text { Rank }\end{array}$ & $\begin{array}{l}\text { Sum of } \\
\text { Ranks }\end{array}$ \\
\hline $\begin{array}{l}\text { Post } \\
\text { test - }\end{array}$ & $\begin{array}{l}\text { Negative } \\
\text { Ranks }\end{array}$ & $23^{\mathrm{a}}$ & 55.26 & $\begin{array}{r}1271.0 \\
0\end{array}$ \\
\hline \multirow[t]{3}{*}{$\begin{array}{l}\text { Pret } \\
\text { est }\end{array}$} & $\begin{array}{l}\text { Positive } \\
\text { Ranks }\end{array}$ & $188^{\mathrm{b}}$ & 112.21 & $\begin{array}{r}21095 . \\
00\end{array}$ \\
\hline & Ties & $20^{\mathrm{c}}$ & & \\
\hline & Total & 231 & & \\
\hline \multicolumn{5}{|c|}{ a. Posttest < Pretest } \\
\hline \multicolumn{5}{|c|}{ b. Posttest $>$ Pretest } \\
\hline \multicolumn{5}{|c|}{ c. Posttest $=$ Pretest } \\
\hline
\end{tabular}

Dari Tabel 4 di atas dapat diketahui bahwa pengaruh yang terjadi bersifat positif. Ini berarti bahwa pemberian pelatihan menulis kreatif mampu meningkatkan keterampilan menulis dongeng anak pada subjek penelitian. Pelatihan menulis kreatif dalam penelitian dapat merangsang munculnya potensi menulis dongeng dalam diri para pendidik PAUD. Mengingat banyaknya manfaat dongeng, maka keterampilan menulis dongeng yang baik pada diri para pendidik PAUD tentu akan sangat bermanfaat tidak hanya untuk meningkatkan kualitas kemampuan profesional mereka tetapi juga untuk meningkatkan keberhasilan pembelajaran yang dilakukan di dalam maupun di luar kelas karena banyak sekali aspek perkembangan anak usia dini yang dapat diasah melalui kegiatan mendongeng.

Temuan dari hasil penelitian ini rupanya sejalan dengan hasil penelitian Sutarma dan Adnyana (Sutarma \& Adnyana, 2014) yang menunjukkan bahwa pembelajaran menulis kreatif dapat meningkatkan kemampuan menulis. Selain itu, bukti empiris yang dihasilkan oleh penelitian ini terkait meningkatnya keterampilan menulis dongeng anak setelah dilakukan pelatihan menulis kreatif sesuai juga dengan pendapat Tarigan
Pengaruh Pemberian Pelatihan....

Rosa Imani Khan', Widi Wulansari2

dan Akadiah (dalam Sidiq et al., 2013), bahwa keterampilan menulis bisa diperoleh dan dikuasai melalui praktik dan latihan. Ketrampilan menulis bukanlah kemampuan kemampuan yang diturunkan/diwariskan, melainkan merupakan hasil proses belajar dan ketekunan dalam berlatih. Untuk mendapatkan keterampilan menulis, termasuk menulis dongeng anak, tidak akan cukup hanya dengan mempelajari tata bahasa dan teori-teori tentang menulis, namun dapat tumbuh melalui proses pelatihan, termasuk pelatihan menulis kreatif.

Terdapat penjelasan hasil penelitian lain lagi yang mendukung temuan dari penelitian ini, bahwa secara teoritis, pengetahuan teknis seseorang tentang menulis tidaklah menjamin ia mampu menulis dengan baik karena menulis bukanlah sebuah keterampilan yang instan. Cara terbaik untuk memperleh keterampilan menulis, terbaik menulis dongeng anak, yang baik adalah dengan mendapatkan pelatihan menulis, termasuk menulis kreatif (Wardiah, 2016).

\section{SIMPULAN}

Secara teoritis, pengetahuan teknis seseorang tentang menulis tidaklah menjamin ia mampu menulis dengan baik karena menulis bukanlah sebuah keterampilan yang instan. Cara terbaik untuk memperleh keterampilan menulis, terbaik menulis dongeng anak, yang baik adalah dengan mendapatkan pelatihan menulis, termasuk menulis kreatif Kesimpulan yang dapat ditarik dari penelitian ini adalah pelatihan menulis kreatif terbukti memberikan pengaruh yang signifikan terhadap keterampilan menulis dongeng anak. Saran yang dapat diberikan oleh peneliti yakni memandang banyaknya manfaat penting dari dongeng untuk perkembangan kualitas anak sebagai generasi penerus bangsa, maka diperlukan upaya untuk mengembangkan keterampilan menulis dongeng, agar budaya mendongeng dapat tumbuh subur lagi di kalangan masyarakat yakni melalui kegiatan pelatihan menulis kreatif. 


\section{DAFTAR PUSTAKA}

Antara, A. (2017). Mengapa Anak Sangat Menyukai Gadget? Begini Penjelasannya. Okezone.Com.

https://lifestyle.okezone.com/read/2017/11/2 7/196/1821466/mengapa-anak-sangatmenyukai-gadget-begini-penjelasannya

Basyiroh, I. (2017). Program Pengembangan Kemampuan Literasi Anak Usia Dini. Tunas Siliwangi, 3(2), 120-134. http://www.ejournal.stkipsiliwangi.ac.id/index.php/tunassiliwangi/article/viewFile/646/476

Chusna, P. A. (2017). Pengaruh Media Gadget Pada Perkembangan Karakter Anak. Dinamika Penelitian: Media Komunikasi Sosial Keagamaan, 17(2), 315-330. https://doi.org/10.21274/dinamika/2017.17.2 .315-330

Danandjaja, J. (1994). Folklor Indonesia: Ilmu Gosip, Dongeng, dan lain-lain. PT Temprint.

Elia, I., van den Heuvel-Panhuizen, M., \& Georgiou, A. (2010). The role of pictures in picture books on children's cognitive engagement with mathematics. European Early Childhood Education Research Journal, 18(3), 275-297. https://doi.org/10.1080/1350293X.2010.500 054

Islami, N. (2017). Pengaruh Gadget pada Anak. Kominfo.Go.Id. https://kominfo.go.id/content/detail/10161/p engaruh-gadget-pada-anak/0/sorotan_media

Kuder, S., \& Hasit, C. (2002). Enhanching Literacy for All Student. Pearson Education Inc.

Kurniawan, H. (2009). Anak dalam Kajian Strukturalisme, Sosiologi, Semiotika, Hingga Penulisan Kreatif. Graha Ilmu.

Latipun. (2002). Psikologi Eksperimen. Universitas Muhammadiyah Malang Press.

Latipun. (2006). Psikologi Eksperimen (2nd ed.). Universitas Muhammadiyah Malang Press.

Lowe, G. (2006). Health-Related Effects of Creative and Expressive Writing. Health Education, 106(1), 60-70. https://doi.org/10.1108/09654280610637201

Novrialdy, E. (2019). Kecanduan Game Online pada Remaja: Dampak dan Pencegahannya. Buletin Psikologi, 27(2), 148. https://doi.org/10.22146/buletinpsikologi.47 402

Nurgiyantoro, B. (2005). Sastra Anak: Pengantar Pemahaman Dunia Anak. Gadjah Mada University Press.

Priyono, K. (2001). Terampil Mendongeng. PT. Grasindo.
Rosidi, I. (2009). Menulis Siapa Takut. Kanisius.

Saputra, N. E., \& Ekawati, Y. N. (2017). Permainan Tradisional sebagai Upaya Meningkatkan Kemampuan Dasar Anak. Jurnal Psikologi Jambi, 2(2), 47-53. https://doi.org/https://doi.org/10.22437/jpj.v 2i2.4796

Sidiq, S., Pramono, W. B., \& Damayanti, A. (2013). Pelatihan Menulis Kreatif untuk Mengembangkan Potensi dan Kreativitas Anak. Jurnal Inovasi Dan Kewirausahaan, 2(3), 217-223. https://journal.uii.ac.id/ajie/article/download/ $7881 / 6890$

Singh, V. K., Singh, A. K., \& Giri, A. (2016). A Study of The Relationship between Scientific Attitude and Academic Achievement of Rural Area's Intermediate College Girls (Science Stream Only). International Journal of Applied Research, 2(4), 46-49. https://www.allresearchjournal.com/archives /2016/vol2issue4/PartA/2-3-75.pdf

Sutarma, I. G. P., \& Adnyana, I. B. A. (2014). Pembelajaran Menulis Kreatif Berbasis Metode Quantum Writing pada Mahasiswa Program Studi D-4 (S-1 Terapan) Manajemen Bisnis Pariwisata, Jurusan Pariwisata, Politeknik Negeri Bali. Aksara, 26(1), 75-85. https://aksara.kemdikbud.go.id/jurnal/index. php/aksara/article/view/146

Syafryadin, S., \& Boulahnane, S. (2021). Immersing Japanese Students into English Language Learning: Songs, Games and Cultures. Cakrawala Pendidikan, Jurnal Pendidikan Ilmiah, 40(3), 554-563. https://doi.org/10.21831/cp.v40i3.37153

Syahra, R. (2006). Informatika Sosial. Peluang dan Tantangan. LIPI.

Tarigan, H. G. (1994). Menulis: Sebagai Suatu Keterampilan Berbahasa. Angkasa.

Utomo, S. B. (2013). Mendongeng Dalam Perspektif Pendidikan. Agastya: Jurnal Sejarah Dan Pembelajarannya, 3(01), 1-8. https://doi.org/10.25273/ajsp.v3i01.901

Wardiah, D. (2016). Increasing The Ability Writing Short Stories through Metacognitive Strategies. IJLECR - International Journal of Language Education and Culture Review, 2(1), 92-101. https://doi.org/10.21009/IJLECR.021.020

Witarsa, R., Mulyani, R. S., Urhananik, \& Haerani, N. R. (2018). Pengaruh Penggunaan Gadget terhadap Kemampuan Interaksi Sosial Siswa Sekolah Dasar. Pedagogik, VI(1), 9-20. 
P ISSN 2548-6284 E ISSN 2615-0360

Vol. 6 No. 1 Desember 2021

Wiyanto, A. (2004). Keterampilan Menulis Paragraf. PT. Raja Grafindo Perkasa.

Yunus, S. (2015). Kompetensi Menulis Kreatif. PT. Raja Grafindo Perkasa. 